\title{
Creep Stress Failure in High Voltage Transformer Interwinding Insulation
}

\author{
P. M. Mitchinson ${ }^{1}$, P. L. Lewin ${ }^{1}$, G. Chen ${ }^{1}$ and P. N. Jarman ${ }^{2}$ \\ ${ }^{1}$ School of Electronics and Computer Science, University of Southampton, Southampton SO17 1BJ, UK \\ ${ }^{2}$ National Grid, National Grid House, Warwick Technology Park, Gallows Hill, Warwick CV34 6DA, UK \\ *E-mail: pmm04r@ecs.soton.ac.uk
}

\begin{abstract}
Three phase transformers have an insulation system which is a complex three dimensional structure of paper and pressboard surrounding the conductors immersed in a large volume of mineral oil. In core form transformers, a key insulation area is the region between adjacent phases which is often reinforced with vertical pressboard barriers. At the higher voltages, these pressboard barriers provide a crucial element in the insulation structure between the phases. The barriers are subjected to large electrical and thermal stresses. The pressboard barriers sit in the time varying electric field pattern generated from the transformer winding coils which are operating with $\mathbf{1 2 0}^{\circ}$ phase difference. The electric field can be resolved along the surfaces of the pressboard and this is termed creep stress or tangential stress. This electric stress can lead to surface tracking along the oil-pressboard boundary layer. A large scale test facility has been developed to investigate the effects of creep stress with the goal of understanding the onset of surface tracking on the pressboard. This paper details the main features of the test platform and control equipment. Finally, the paper includes some initial results of experiments conducted to detect partial discharge under two temperature conditions.
\end{abstract}

\section{INTRODUCTION}

In simple terms, a three-phase core type transfomer comprises three cylindrical coils placed side by side within a containment vessel. However, the construction of the insulation system is anything but simple being a complex combination of paper, pressboard and mineral oil which exist together in a three dimensional arrangement as required by the design of the transformer in order to achieve the high isolation for the operation requirements between windings. The structure includes helical, cylindrical, planar and cubic shapes of both paper and pressboard of various dimensions around and in between the windings. The windings are completely immersed in mineral oil, the function of which is to fill the voids between the paper and pressboard and which, by nature, will also impregnate the paper and pressboard. The overall system response is determined by the presence of interfacial boundaries between the metal, oil and paper structures and the different permittivity values of the oil and paper. As the insulation system ages, the paper/pressboard structure is further modified by de-polymerisation of the cellulose molecules and the accumulation of water and other contaminant molecules. One particular region in the construction is the vertical volume between adjacent phase cylinders which is termed the interphase region. Here, for high voltage applications, the oil gap is usually broken by multiple sheets of thick pressboard to form the interphase pressboard barrier region with multiple oil pressboard interfaces. In aged equipment, there have been documented cases where transformer failure has been attributed to flashover from the centre of the high voltage coil of one phase along the surface of the closest pressboard down to ground [1]. The cause of this failure mechansim is as yet unknown and there is a real drive to understand the initiation process of this failure mode.

An experimental platform, designed to simulate the conditions inside a high voltage transformer, has been developed to invetsigate this failure mechanism by placing large sheets of pressboard in a controlled volume of oil. Voltage from different phases are applied to electrodes with the aim of initiating the electric stress, termed creep stress, along the surface of the pressboard. The goal is to understand what factors cause the initiation of tracking along the surface interface in an oil/pressboard insulation medium.

\section{EXPERIMENTAL APPARATUS}

\section{A. General description of apparatus}

The apparatus consists of the experimental platform and an independent bi-phase supply. The bi-phase supply can be varied to enable voltages at different amplitudes and phase to be applied to each side of the oil immersed pressboard.

The platform comprises two chambers; the main chamber termed the test cell and, located above it, the conservator (Fig. 1). The test cell is fitted with two horizontally mounted $71 \mathrm{kV}$ rated bushings through which high voltage from different phases can be applied to the specimen of insulation immersed in oil.

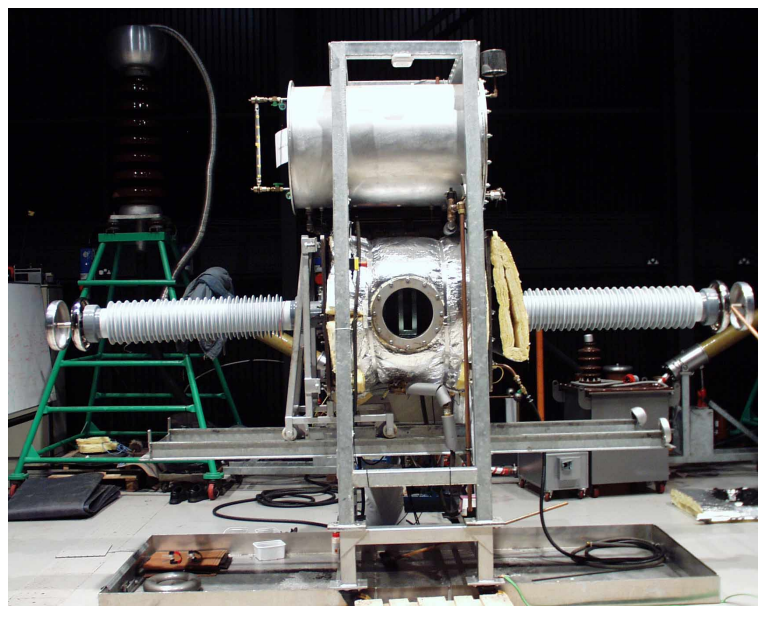

Fig.1. Side view of test platform 
The overall dimensions of the apparatus are $1 \mathrm{~m} \times 3 \mathrm{~m} \times 3 \mathrm{~m}$ approximate with the conservator having a capacity of 425 litres and the test cell a volume of 370 litres. The chambers are coupled by means of a system of interconnecting pipes to allow filling and emptying of the test cell with oil and to enable a vacuum to be applied to the test cell. The conservator allows sufficient reserve for expansion/contraction during heating cycles or fluid storage when access is required to the test cell electrode. Oil from the conservator is allowed into the test cell using either direct gravity feed or under vacuum conditions after first vacuuming the chamber.

The oil is heated in the chamber using a $5 \mathrm{~kW}$ trace heating element coiled around the test cell exterior. Heat is transferred to the oil by conduction but an external pump is also used to circulate the oil within the test cell in order to assist internal convection and, by this means, the oil temperature can be raised at a rate of $12 \sim 14^{\circ} \mathrm{C} / \mathrm{hr}$.

The platform is controlled and monitored using a programmable logic controller (PLC) to ensure safe heating of the oil, fluid transfer and monitoring of the system temperature and valve positions. The test cell pressure and temperatures are monitored by means of sensors fitted around the chamber. The valve positions are detected by means of micro-switches placed on the pipe valves. The test cell is fitted with an independent mechanical safety valve set to $45 \mathrm{kPa}$ gauge pressure. A separate oil conditioning unit is used to purify and/or transfer the oil as necessary. The test cell is the controlled volume in which is mounted the test electrodes and pressboard holder.

\section{B. Test electrodes and pressboard test specimen}

Each test electrode comprises $15 \mathrm{~mm}$ x $2 \mathrm{~mm}$ strip metal bent to present the flat strip towards the plane of the pressboard. The electrode is shaped to form the segment of a circle thus representing the arrangement of the winding sector of a transformer series winding adjacent to the inter-phase barrier board. The electrode is covered in 3 half lapped layers of $0.08 \mathrm{~mm}$ thick electrical grade Kraft paper to give a total thickness of $0.48 \mathrm{~mm}$ The position of the electrode is preadjusted by sliding it in and out of slots on the carrier disk and then securing it onto the carrier disk by grub screws. The carrier disk is inserted a fixed distance into the bushing corona shield and is held at the centre of the test cell (Fig.2). By this means, the distance of the electrode from the plane of the test pressboard can be controlled.

Two electrodes were positioned either side of the pressboard specimen and these were termed the reference electrode $V_{1}$, and control electrode $V_{2}$. A $10 \mathrm{~mm}$ x $2 \mathrm{~mm}$ strip was clamped to the pressboard sheet at a distance of $40 \mathrm{~mm}$ from the edge of the reference electrode to form the third element of the three terminal experiment (Fig.3). This earth bar represents the tank support on which the interphase pressboard is usually mounted.

Under experimental conditions, it was found that no significant PD was initiated until a spike, in the form of a tungsten tip, was introduced into the reference electrode. The spike was embedded so that the tip protruded $3 \mathrm{~mm}$ from the electrode edge and made parallel to the pressboard. The tungsten tip forms the local region of high electric stress which can give rise to a stream of electrons due to field emission [2].

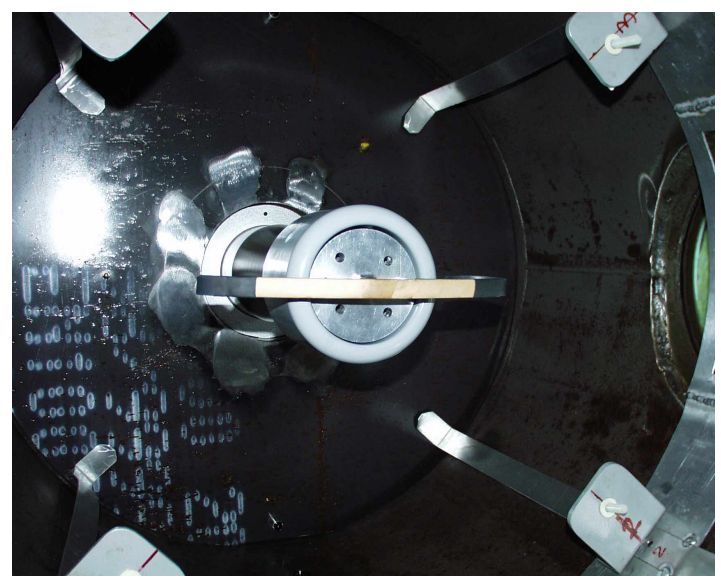

Fig.2. Internal view of test cell showing electrode and carrier on bushing

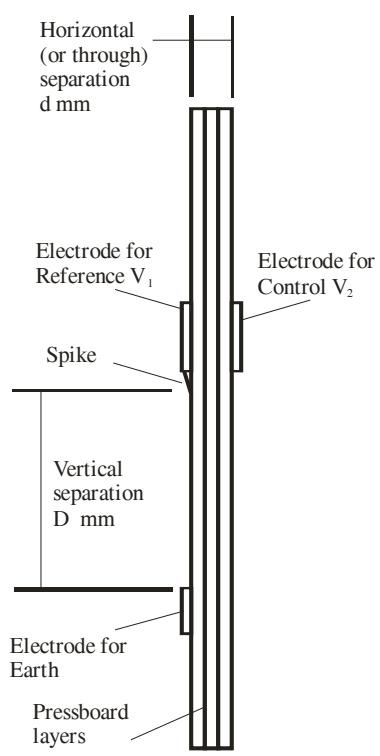

Fig.3. Diagrammatic cross section of test specimen showing arrangement of electrodes and pressboard

The pressboard test specimen is held in the centre of test cell by means of four securing lugs. For the series of experiments, three sheets of pressboard $(450 \mathrm{x} 450 \mathrm{~mm} \times 1.5 \mathrm{~mm}$ thick Transformer Board TIV) were used as the solid insulation medium (approximately $1 \mathrm{~kg}$ total dry mass). The pressboard is widely used in the construction of HV transformers and has a breakdown strength of $40 \mathrm{kV} / \mathrm{mm}$ minimum [3]. Virgin mineral oil (Nynas Nytro 10GBN batch ISHL HDS/137) was used as the liquid dielectric. This oil is an un-inhibited hydrotreated light naphthenic distillate mineral oil with a typical aromatic content of $14 \%$ and minimum breakdown strength of $30 \mathrm{kV} / \mathrm{mm}[4]$. 


\section{Bi-phase supply}

The bi-phase supply comprises two independent voltage controlled sources. One is used as the reference source and is applied to a $380 \mathrm{~V} / 200 \mathrm{kV}$ PD-free Haefely transformer. The output is the reference voltage $\left(\mathrm{V}_{1}\right)$ and is taken through one bushing and applied to one side of the pressboard via the shaped electrode. Synchronised to the reference source is the independent control source. This is generated by means of a low voltage variable phase generator and amplified through a power amplifier. This voltage is applied to a $240 \mathrm{~V} / 100 \mathrm{kV}$ PD-free Agea Kull transformer. The output, which provides the control voltage $\left(\mathrm{V}_{2}\right)$, is taken through the other bushing and applied to the other side of the pressboard via a similarly shaped electrode. The straight bar, which is connected to earth, forms the third element of the three electrode system. By this means, the control voltage $\mathrm{V}_{2}$ can be varied in both amplitude and phase $\phi, 0^{\circ}$ to $360^{\circ}$ elec. with respect to the reference voltage $\mathrm{V}_{1}$. The two voltages interact to give a resultant voltage vector which can be resolved into two orthogonal components; one gives rise to the tangential or creep stress $\left(\mathrm{E}_{\text {creep }}\right)$ along the surface of the pressboard and the other gives rise to a stress $\left(\mathrm{E}_{\text {Perpendicular }}\right)$ through the pressboard which is perpendicular to the creep stress (Fig.4).

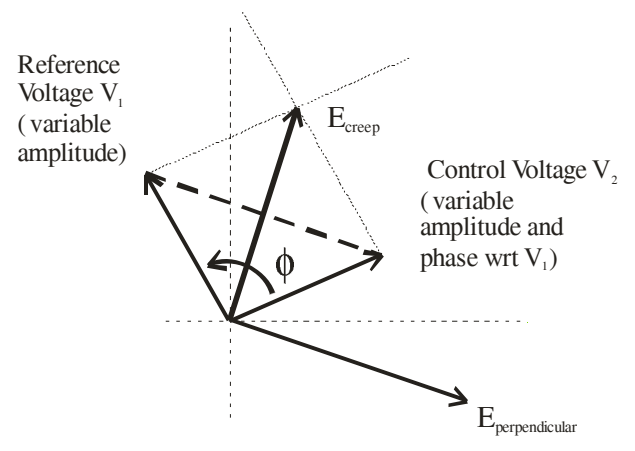

Fig.4. Phasor diagram of voltage interaction

For small mechanical angles (i.e. D >>d in Fig. 3), the creep stress along the surface of the pressboard is:

$$
\begin{aligned}
\overrightarrow{\mathrm{E}}_{\text {creep }} & =\left[\overrightarrow{\mathrm{v}}_{1}+\overrightarrow{\mathrm{v}}_{2}\right] / \mathrm{D} \\
& =\left[\mathrm{V}_{1} \operatorname{Sin} \omega \mathrm{t}+\mathrm{V}_{2} \operatorname{Sin}(\omega \mathrm{t}-\phi)\right] / \mathrm{D}
\end{aligned}
$$

Similarly, the through stress or perpendicular stress is:

$$
\begin{aligned}
\overrightarrow{\mathrm{E}}_{\text {Perpendicular }} & =\left[\overrightarrow{\mathrm{v}}_{1}-\overrightarrow{\mathrm{v}}_{2}\right] / \mathrm{d} \\
& =\left[\mathrm{V}_{1} \operatorname{Sin} \omega \mathrm{t}-\mathrm{V}_{2} \operatorname{Sin}(\omega \mathrm{t}-\phi)\right] / \mathrm{d}
\end{aligned}
$$

This suggests that maximum creep stress will occur when the two voltages are in phase and the maximum perpendicular stress will occur when the two voltages are in anti-phase. As the control voltage is moved in and out of phase with respect to reference voltage, there occurs phase angles, at which partial discharge inception and extinction occur.
With full independent control of the two phases, the creep stress and perpendicular stress can be controlled independently to assess the effects of the interaction between them. Also, unbalanced voltage conditions, such as neutral inversion or phase faults which may occur transiently within transformers [5], can be modelled.

\section{EXPERIMENTAL PROCEDURE}

\section{A. Pressboard sample preparation}

Clean pressboard was dried in an electrically heated free breathing oven at $105^{\circ} \mathrm{C}$ for a minimum of 12 hours. The pressboard was considered "dry" when the board mass was found unchanged after 3 successive measurements. To achieve a target percentage of moisture content, the dried pressboard samples were left under normal atmospheric conditions to absorb moisture until the mass had increased by the required amount from the dried condition. The conditioned pressboard was then placed in the test chamber. For this study, the boards were allowed to regain a moisture mass of $7 \%$, inserted into the test chamber and a vacuum drawn. When the vacuum level of $35 \mathrm{mbar}$ had been reached, the vacuum process was stopped and the chamber filled with the degassed clean mineral oil.

\section{B. Moisture content of the oil and pressboard}

The moisture content of the oil was monitored using the Karl Fisher Titration technique. The oil moisture was measured at between $10 \sim 16 \mathrm{ppm}$. On account of the large oil: pressboard ratio (330:1 by mass), a change of $1 \mathrm{ppm}$ of moisture content in the oil corresponds to 0.3 gram of water absorbed/desorbed by the pressboard. With the mass of dry pressboard at 990 grams approximate, this represents a change of $0.4 \%$ in pressboard moisture from the initial moisture content of $7 \%$ per ppm change in oil moisture. Thus, the moisture content in the pressboard effectively remains stable.

\section{Data collection}

The test cell was fitted with a three-ply sheet of pressboard conditioned to $7 \%$ moisture, impregnated with oil and allowed to achieve equilibrium at room temperature for 12 hours minimum before conducting PD tests at a fixed system temperature.

The voltage on the reference electrode was set at a fixed value $V_{1}$. The voltage on the control electrode $V_{2}$ was raised in anti-phase with $V_{1}$ until PD was detected. The phase angles, at which inception and extinction of PD occurred, were noted. This was then repeated at higher levels of control voltage to measure the PD under perpendicular stress conditions. The procedure was repeated with $V_{2}$ in phase with $V_{1}$ to measure the PD under creep stress conditions. PD inception and extinction activity was recorded at system temperatures of $20^{\circ} \mathrm{C}$ and $40^{\circ} \mathrm{C}$.

A Robinson Model 700 PD detector calibrated to $50 \mathrm{pC}$ was used to detect PD. The threshold level for background noise was determined at $2 \mathrm{pC}$. 


\section{RESULTS}

A. Phase to anti-phase (Perpendicular stress)

Significant PD activity was recorded at $20^{\circ} \mathrm{C}$ and $40^{\circ} \mathrm{C}$. Figs. 5 and 6 show the resultant inception and extinction angles at which PD was observed as the phase angle of the control voltage was adjusted with a lagging and leading aspect with respect to $180^{\circ}$ elec. of the reference voltage.

\section{B. Phase to phase (Creep stress)}

No PD activity was recorded at $20^{\circ} \mathrm{C}$ with reference and control voltages up to $27.5 \mathrm{kV}$. At $40^{\circ} \mathrm{C}$, PD activity was just discernable with voltage of $25 \mathrm{kV}$ on each phase suggesting that temperature may play a role in surface tracking.

\section{CONCLUSIONS}

A large scale test facility has been developed to investigate the mechanism of surface tracking and inter-phase breakdown.

An initial experiment has been completed with clean oil and with new but wet, uncontaminated pressboard. Under these conditions, significant PD activity was observed under phase to anti-phase set-up with large through stress. On the other hand, no significant PD activity due to creep stress was recorded under the experimental conditions with phase to phase set-up.

In the phase to anti-phase voltage configuration, there is a minimum voltage difference (difference voltage onset) above which significant PD activity occurs. For a fixed reference voltage, the phase angles, at which inception and extinction occur, increase with increasing control voltage. The angles of inception and extinction are also wider for a leading control voltage than for a lagging control voltage. This suggests that the leading voltage is tending to sustain the PD activity more than the lagging voltage.

In the phase to phase configuration, the initial results have suggested that surface tracking is unlikely under clean conditions even with significantly wet pressboard.

Further work is being undertaken to understand the relationship between creep stress and high temperature, pressboard age (i.e. surface contamination) and oil condition.

\section{ACKNOWLEDGEMENT}

The authors acknowledge the support of National Grid, UK in funding the project.

\section{REFERENCES}

[1] J. A Lapworth, P. N. Jarman, T Breckenridge, "Transformer internal overvoltages caused by remote energisation," Paper A2-305 Cigré 2006.

[2] E. Kuffel, W. S, Zaengl, J. Kuffel. "High Voltage Engineering: Fundamentals." $2^{\text {nd }}$ Edition, Butterworth -Heinemann, 2000.

[3] Transformer Board T IV Product Data Sheet, Weidmann Systems International

[4] Nynas Transformer oil Nitro 10GBN, Product Data Sheet, date 2005-0820. Nynas Naphthenics AB.

[5] "Modern Power Station Practice", $3^{\text {rd }}$ Edition, Volume D: Electrical Systems and Equipment. British Electricity International, Oxford, Pergamon Press. 1992.

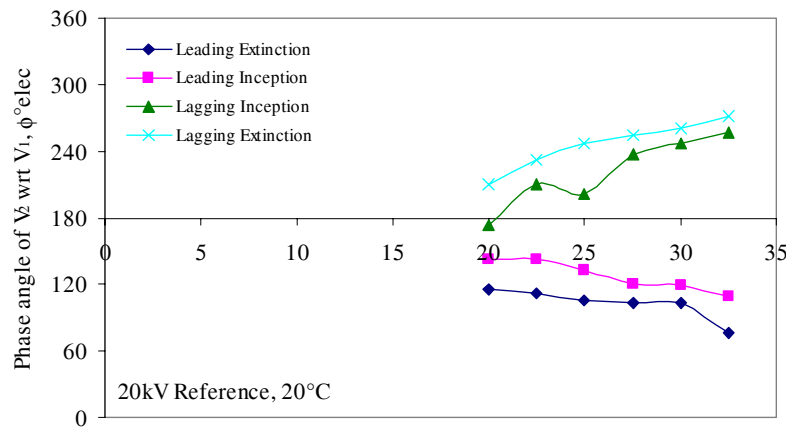

Control Voltage $\mathrm{V}_{2}, \mathrm{kV}$

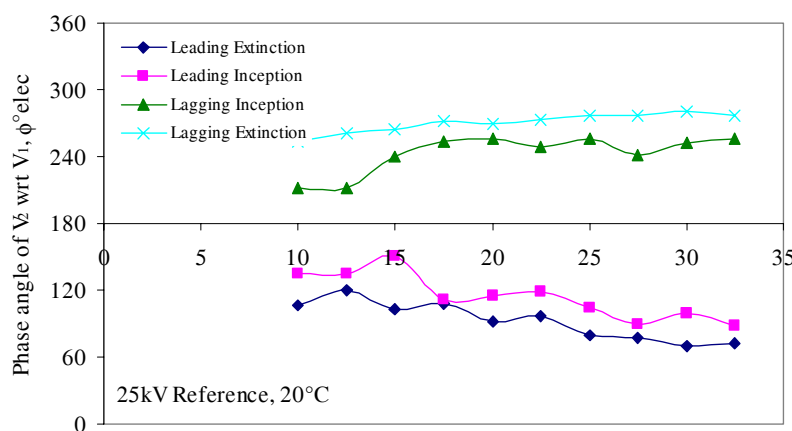

Control Voltage $\mathrm{V}_{2}, \mathrm{kV}$

Fig.5. PD inception and extinction due to Perpendicular stress at $20^{\circ} \mathrm{C}$

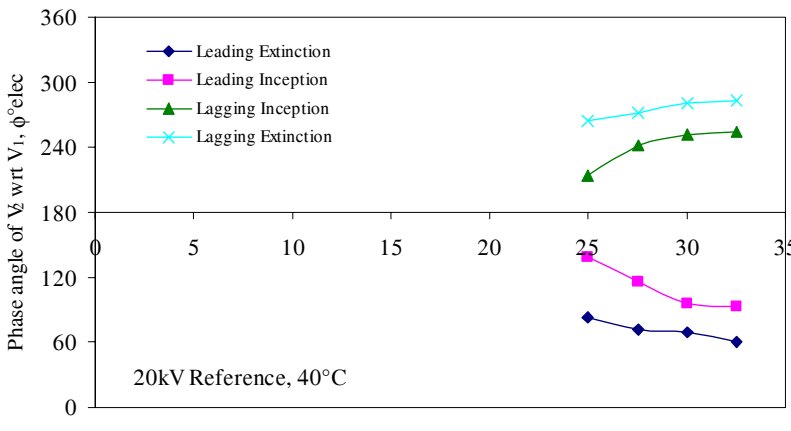

Control Voltage $\mathrm{V}_{2}, \mathrm{kV}$

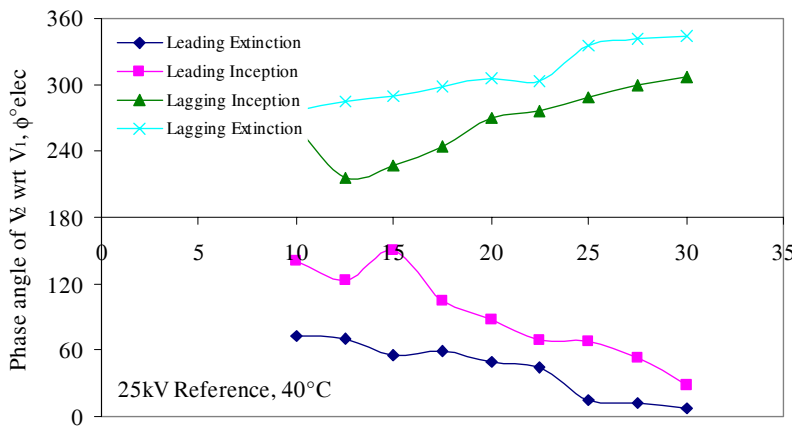

Control Voltage $\mathrm{V}_{2}, \mathrm{kV}$

Fig.6. PD inception and extinction due to Perpendicular stress at $40^{\circ} \mathrm{C}$ 